\title{
Finite element analysis of adaptive-stiffening and shape-control SMA hybrid composites
}

\author{
Xiujie Gao ${ }^{\mathrm{ab}}$, Travis L. Turner ${ }^{\mathrm{c}}$, Deborah Burton ${ }^{\mathrm{a}}$ and L. Catherine Brinson**ab \\ ${ }^{\mathrm{a}}$ Department of Mechanical Engineering, Northwestern University, Evanston, IL 60208 \\ ${ }^{\mathrm{b}}$ Department of Materials Science \& Engineering, Northwestern University, Evanston, IL 60208 \\ ${ }^{c}$ NASA Langley Research Center, Structural Acoustics Branch, Mail Stop 463, Hampton, VA 23681
}

\begin{abstract}
The usage of shape memory materials has extended rapidly to many fields, including medical devices, actuators, composites, structures and MEMS devices. For these various applications, shape memory alloys (SMAs) are available in various forms: bulk, wire, ribbon, thin film, and porous. In this work, the focus is on SMA hybrid composites with adaptive-stiffening or morphing functions. These composites are created by using SMA ribbons or wires embedded in a polymeric based composite panel/beam. Adaptive stiffening or morphing is activated via selective resistance heating or uniform thermal loads. To simulate the thermomechanical behavior of these composites, a SMA model was implemented using ABAQUS' user element interface and finite element simulations of the systems were studied. Several examples are presented which show that the implemented model can be a very useful design and simulation tool for SMA hybrid composites.
\end{abstract}

Keywords: shape memory alloys, Nitinol, ABAQUS, finite element analysis, post-buckling control, shape control, deflection control, adaptive stiffening, morphing, constitutive modeling, user element

\section{INTRODUCTION}

Shape memory alloys (SMA) are a group of smart metals that recover particular shape when heated above their transformation temperatures (shape memory effect) or removal of load (superelastic effect). The ability to have large recoverable shape change has found great ever-growing interest in adaptive materials and structures. US government and agencies have established several programs/projects to fund research in such areas including the DARPA Smart Wing Project, the NASA AVST Morphing Project, the Morphing Aircraft Structures (MAS) Program, the Smart Materials and Structures Demonstrations Program, and the Synthetic Multifunctional Materials (SMFM) Program. The major motivation behind these projects is to enable efficient, multi-point adaptability in air, space and water vehicles to reduce drag, noise, vibration or acoustic signature and increase endurance, ballistic/blast protection and dynamic response.

A number of different types of adaptive SMA composites use SMA wires or ribbons embedded in a matrix. Matrix materials that have been used include polymers [1;2], metals [3-5], plaster [6], and composites such as fiberglass-epoxy $[7 ; 8]$ and carbon-epoxy [9]. Some applications use the SMA behavior to control the shape of the composite structure $[10-12]$, or its vibrational $[7 ; 13 ; 14]$ or buckling response $[15 ; 16]$ while other applications use the SMA components to change the composite's stiffness [7;17], to strengthen the composite [4], and to close or repair cracks [8;18-20]

Several methods have been developed to study the thermomechanical response for SMA composites, including micromechanical methods [18;21] and finite element analysis [15;22; 23]. In some cases, special composite elements have been created to study multi-layered composite plates [24-26] and layered beams [27]. Other approaches model the matrix and SMA reinforcing members separately for composite beams actuated by SMA wires or ribbons [22; 23]. In a recent finite element analysis for buckling of a laminated composite shell, the SMA elements were modeled as 1D wire elements, but twinned martensite was not considered [15].

Extensive experimental and modeling work has also been conducted on active SMA polymer composites by Turner and his collaborators at NASA Langley Research Center [28-33]. Figure 1 shows a conceptual airplane with morphing airfoil

* cbrinson@,northwestern.edu, phone 1-847-467-2347, fax 1-847-491-3915

http://www.mech.northwestern.edu/dept/people/faculty/brinson.html 
made of shape memory alloy hybrid composite and the adaptive stiffening prototype beam at NASA undergoing a temperature ramp test. In early work, Turner [34] developed the ECTE (effective coefficient of thermal expansion) model to describe behavior of active SMA composites. This ECTE model only needs measurement of the fundamental engineering properties such as stress and Young's modulus for the intended use condition (e.g., prestrain level and constraint) and the model prediction correlates very well to experiments under the intended condition. However, some limitations of the ECTE model are that reorientation effects and cyclic loading or partial loading/unloading are not readily feasible.

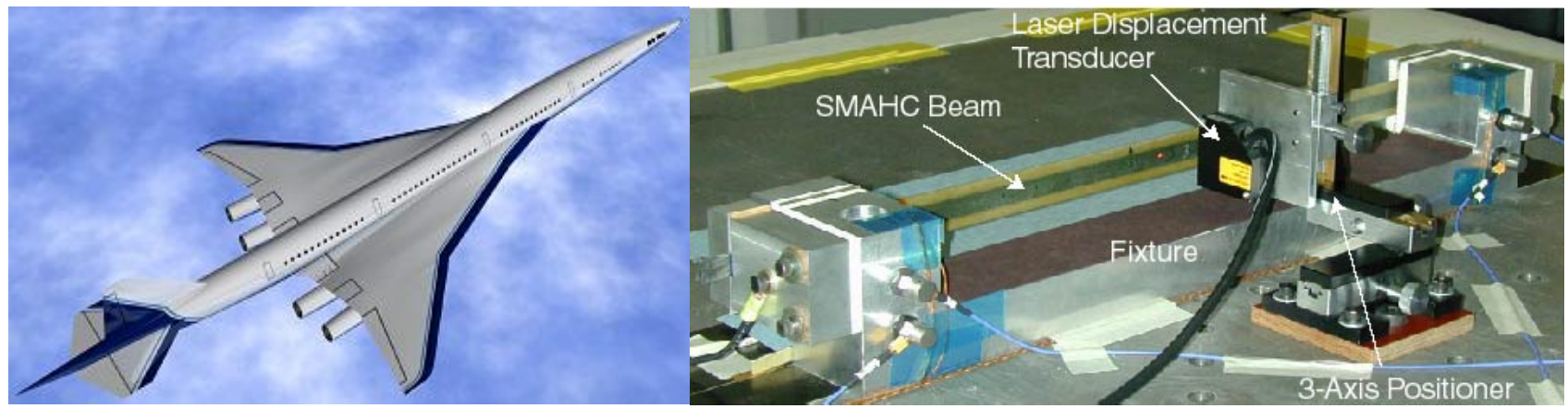

Figure 1: Left) Conceptual airplane with morphing airfoil made of shape memory alloy hybrid composite; Right) Adaptive stiffening prototype beam at NASA undergoing a temperature ramp test [28].

The intent of this paper is to demonstrate and validate another approach in modeling such active composites. Here we model the matrix material using standard elements of ABAQUS and model the SMA reinforcing elements using a rigorous 1D shape memory alloy constitutive model through ABAQUS' user element interface. The SMA material behavior in these composites is primarily one-dimensional since the SMA components act mainly by a change in their length with no significant non-uniaxial forces. A brief discussion of 1D models is given in the next section and the readers is referred to $[35 ; 36]$ for more discussion on such models. Several example problems are simulated and shown and implications are discussed.

\section{CONSTITUTIVE MODEL AND FINITE ELEMENT IMPLEMENTATION}

The SMA constitutive model used is based on a model originally formulated by Tanaka [37], and modified by Liang and Rogers [38] and subsequently by Brinson [39-41]. The one-dimensional model is based on phenomenological macroscale constitutive behavior and can be written as

$$
\sigma=\mathrm{E}\left(\varepsilon-\varepsilon_{\mathrm{L}} \xi_{\mathrm{S}}\right)+\Theta \Delta \mathrm{T}
$$

where $\sigma$ is stress and $\varepsilon$ is strain; $\xi_{\mathrm{s}}$ is the stress-induced martensite fraction, $E$ is the elastic modulus, $\varepsilon_{L}$ is the maximum transformation strain, and $\Theta$ is related to the thermal coefficient of expansion for the material.

Coupled to the constitutive law, a kinetic law must be used to determine the martensite volume fraction based on the stress and temperature loading history. The transformation criteria can be represented on an experimentally determined phase diagram shown in Figure 2. The kinetic law used in the simulations for this paper includes both twinned and detwinned martensite variants [39], as is essential to properly handle the issue of martensitic variant reorientation. The kinetics are further enhanced to consider the full thermomechanical history implemented through "switching points" for changes in load path direction [41]. This allows the model to appropriately model hysteresis effects in the phase transformation and to capture cyclic or repetitive loading conditions, under which many kinetic laws fail. The reader is referred to the previous work for a full explanation and examples of the algorithms and only a brief synopsis is presented here for transformation between the $[\mathrm{M}]$ and $[\mathrm{A}]$ regions.

Whenever the thermomechanical state of the SMA material enters the shaded areas on the diagram of Figure 2, $\xi_{\mathrm{s}}$ must be updated. The thermomechanical path can be complex and the kinetic algorithm described here to update $\xi_{\mathrm{s}}$ is able to consistently reproduce the path dependence of martensitic transformation. Note in Figure 2 that the normal vectors $\mathbf{n}_{\mathrm{A}}$ and $\mathbf{n}_{\mathrm{M}}$ represent the directions of transformation change in the $[\mathrm{A}]$ and $[\mathrm{M}]$ strips respectively. At any point on the path, $\tau$ is the vector tangent to $\Gamma$. A transformation occurs whenever one of the following conditions is satisfied: 
a) $\tau \cdot \mathbf{n}_{\mathrm{A}}>0$ in $[\mathrm{A}]$

b) $\tau \cdot \mathbf{n}_{\mathrm{M}}>0$ in $[\mathrm{M}]$

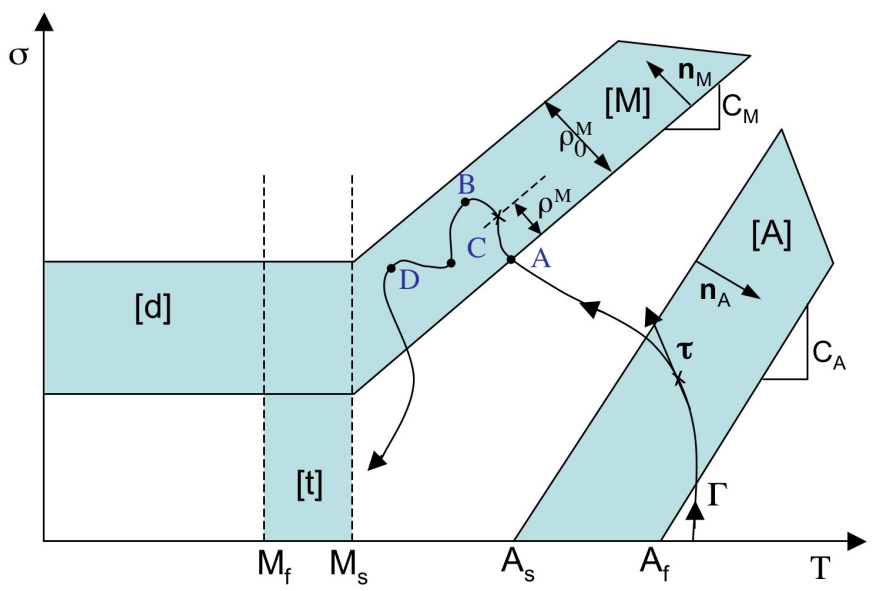

Figure 2: Typical phase diagram for a shape memory alloy. [M], [A], [d] and [t] are regions of transformation between martensite and austenite. $[\mathrm{M}]$ and $[\mathrm{d}]$ are associated with formation of detwinned martensite (with accompanying macroscopic strain), while $[\mathrm{t}]$ is associated with twinned martensite (no accompanying macroscopic strain). A thermomechanical loading path, $\Gamma$, is shown with several switching points indicated by solid circles. Loading path tangent, $\tau$, and transformation strip distances, $\rho$, are indicated. At high $\sigma$ and T, SMAs have a zone of irreversible plastic deformation which is not shown in this figure. The composite is loaded so that SMA wires do not enter this region as it is not useful for self-healing.

A given loading path $\Gamma$ can be subdivided into several segments $\left(\Gamma_{n}, n=1,2 \ldots\right)$ by introducing the switching points, defined as the points where the direction or sense of the transformation changes. The switching points are points where $\Gamma$ enters or leaves the transformation strip in the direction of transformation (point A) or points inside the strip where the dot product between $\tau$ and $\mathbf{n}_{\mathrm{A}}$ or $\mathbf{n}_{\mathrm{M}}$ changes sign (points B, C, D). Along the portions of $\Gamma$ between two switching points, $\xi_{s}$ is monotonically either increasing or decreasing (when in a transformation strip and moving in a transformation direction, e.g. between $\mathrm{A}$ and $\mathrm{B}$ or $\mathrm{C}$ and $\mathrm{D}$ ) or constant (when outside a transformation strip or when moving opposite to the transformation direction, e.g. between $\mathrm{B}$ and $\mathrm{C}$, or along any portions of $\Gamma$ outside of the segment A to D).

Bekker and Brinson [41] present three ways to formulate the local kinetic law, one of which is utilized here. We first define $\mathrm{Y}^{i}=\mathrm{Y}^{i}(\mathrm{~T}, \sigma),(i=\mathrm{A}, \mathrm{M})$ as the normalized distance between a given point on $\Gamma$ inside a transformation strip and the start boundary. $\mathrm{Y}^{i}$ is given by the following expression

$$
\mathrm{Y}^{i}=\frac{\rho^{i}}{\rho_{0}^{i}},
$$

where $\rho^{i}$ is the distance of point $(\mathrm{T}, \sigma)$ from the start boundary, and $\rho_{0}^{i}$ is the width of the strip. Figure 2 illustrates these quantities for the case of the $[\mathrm{M}]$ strip.

On a given portion $\Gamma_{n}$ between two switching points, $\xi_{\mathrm{s}}$ can then be updated using the appropriate one of the following expressions

$$
\xi_{\mathrm{S}}=\xi_{\mathrm{Sj}} \mathrm{f}^{\mathrm{A}}\left(\mathrm{Y}^{\mathrm{A}}-\mathrm{Y}_{\mathrm{j}}^{\mathrm{A}}\right)
$$

when the point is inside the [A] strip, and

$$
\xi_{\mathrm{S}}=\xi_{\mathrm{Sj}}+\left(1-\xi_{\mathrm{Sj}}\right) \mathrm{f}^{\mathrm{M}}\left(\mathrm{Y}^{\mathrm{M}}-\mathrm{Y}_{\mathrm{j}}^{\mathrm{M}}\right)
$$

when the point is inside the [M] strip. 
In the forgoing expressions, quantities marked with subscript $j$ are the values of the martensite fraction and the normalized distance at the previous switching point relevant to the current transformation, $\xi_{s}$ is the stress-induced martensite fraction and $\mathrm{f}^{j}$ are interpolation functions. Here cosine interpolation functions are used, equivalent to those originally developed by Liang and Rogers [38]:

$$
\begin{aligned}
& \mathrm{f}^{\mathrm{A}}\left(\mathrm{Y}^{\mathrm{A}}-\mathrm{Y}_{j}^{\mathrm{A}}\right)=1-\frac{1}{2}\left\{1-\cos \left[\pi\left(\mathrm{Y}^{\mathrm{A}}-\mathrm{Y}_{j}^{\mathrm{A}}\right)\right]\right\} \\
& \mathrm{f}^{\mathrm{M}}\left(\mathrm{Y}^{\mathrm{M}}-\mathrm{Y}_{\mathrm{j}}^{\mathrm{M}}\right)=\frac{1}{2}\left\{1-\cos \left[\pi\left(\mathrm{Y}^{\mathrm{M}}-\mathrm{Y}_{\mathrm{j}}^{\mathrm{M}}\right)\right]\right\}
\end{aligned}
$$

The Brinson model has been tested and found to be an excellent SMA model for modeling SMA wire reinforced composite structures. [36]. The kinetic and constitutive laws presented here have been implemented successfully for onedimensional SMA response using ABAQUS' user element interface. The SMA user element includes a non-linear (both geometric and material) finite element procedure for the kinetic and constitutive laws, appropriate convergence criteria for both ABAQUS and the user element, tracking of converged and switching points while trying new predictions which may be rejected by ABAQUS. The readers are referred to [42] for more details. For the simulations presented in next section, the SMAs are modeled using the new SMA user element. The matrix is modeled using standard element types available from ABAQUS, since a wide variety of element types are available for laminated composite materials with temperature dependent material properties.

\section{EXAMPLE PROBLEMS AND DISCUSSIONS}

The SMA user element will now be used to model the shape memory alloy reinforcements embedded in metal or polymer matrix. The matrix material elements are modeled using standard element types available in ABAQUS and the SMA wire elements are 1-D truss elements tied at the nodes to the matrix elements. The example cases to be considered include a beam clamped at each end and a cantilevered beam with biased SMA reinforcers undergoing thermal cycling. Nonlinear static analysis of these composites are performed and compared to experimental results. Nonlinear analysis for a self-healing composite going through two fracture-heal cycles had been also performed using similar approaches, and the readers are referred to $[14 ; 35]$ for details.

\subsection{Clamped SMA hybrid composite beam}

For easy comparison the beam specimen considered here is same as the one used by Turner and Patel [33] with slight modifications in the finite element model and mesh to render it suitable for analysis with the 1D SMA user element. The experimental beam specimen is 18 inches long $(45.72 \mathrm{~cm})$ and 1 inch wide $(2.54 \mathrm{~cm})$ and clamped at both ends. The lamination stacking sequence is $(45 / 0 /-45 / 90)_{2 s}$ with SMA ribbon material replacing a width of 0.45 inches $(1.143 \mathrm{~cm})$ of the $0^{\circ}$ glass-epoxy layers about the beam centerline, bounded by $0.275 \mathrm{inch}(0.6985 \mathrm{~cm})$ wide strips of glass-epoxy on either side. The thickness of each glass-epoxy layer is 0.004875 inches $(0.012383 \mathrm{~cm})$ and that for the SMA is 0.006 inches $(0.01524 \mathrm{~cm})$. Therefore, the prototype beam has a thickness of 0.078 inch $(0.1872 \mathrm{~cm})$ on both edges and 0.0825 inch $(0.20955 \mathrm{~cm})$ in the center, whose cross-section is shown on the top plot of Figure 3. Since currently the SMA user element is a 3D truss it cannot occupy a 2D or 3D space. Thus each 2D layer of ribbons is modeled as a $1 \mathrm{D}$ truss element row and due to the symmetry of the layers and the loading, the 4 layers can be consolidated into a single truss element row in the center of the beam with equivalent area. Accordingly the matrix in the center is modeled as 12 layers of glassepoxy having a thickness of 0.0585 inch $(0.14859 \mathrm{~cm})$, as shown in the bottom plot of Figure 3 . The only connection between the truss elements and elements of the matrix is the common nodes along the center. This approximation decreases the moment of inertia of the beam and impacts the quantitative comparison of simulation and experimental results, as mentioned later. A method to wrap the implemented 1D model into pseudo 2D or 3D elements will be discussed later.

In the meshing process, the length of the beam is divided into 36 segments. Since ABAQUS is capable of modeling laminated composite materials given the material and orientation stacking sequence, the matrix on both outer edges (16 layers of glass-epoxy) are modeled using $16 * 36 * 2 \mathrm{~S} 4$ quadrilateral shell elements and $12 * 36 * 2$ for the center (12 layers of glass-epoxy). The SMA ribbons are modeled with 36 truss elements sharing some common nodes with the $4 * 36 * 2$ 
shell elements close to the central line. The in-plane (top) view of the beam specimen is shown in Figure 4, with $36 * 4$ matrix elements in a layer and crosses indicating the left end of user elements.

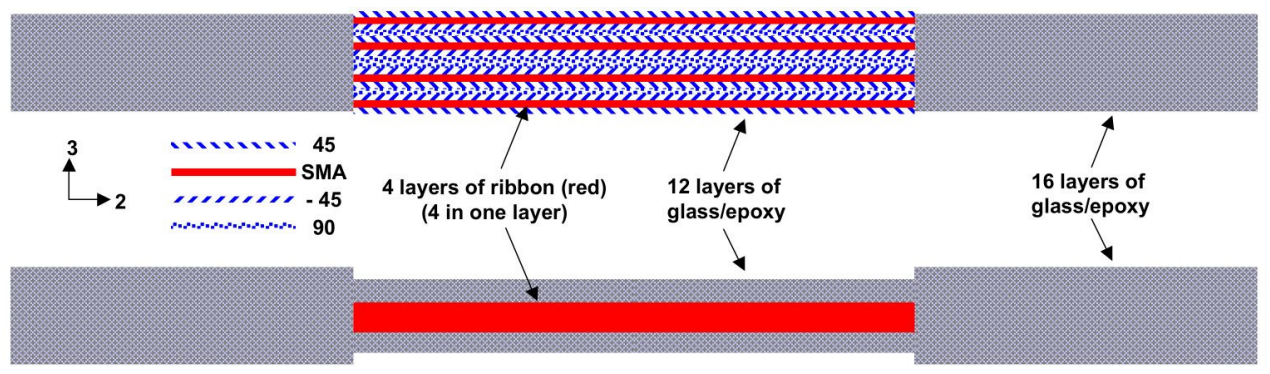

Figure 3: Top) Schematic of the cross-section of the adaptive stiffening prototype beam and Bottom) Finite element model

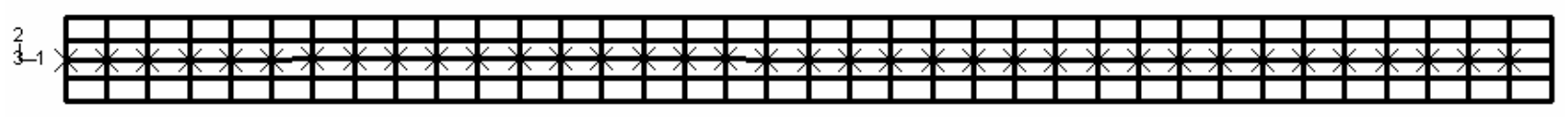

Figure 4: In-plane view (top view) of the adaptive-stiffening SMA hybrid composite beam specimen ( $36 \mathrm{x} 1$ inch), with $36 * 4$ matrix elements in a layer and crosses indicating the left end of user elements.

The properties used in this study for the SMA materials are listed in Table 1. Among these properties, the Young's modulus of austenite, the Poisson's ratio and density are same as those in [33], with the Young's modulus of the martensite being half of the austenite. The transformation temperatures are based on DSC test results in [30]. The phase diagram parameters and the max residual strain were not available for the SMA ribbon used in the composite and values were taken from $[38 ; 43 ; 44]$ for a similar NiTi material. The thermal coefficient of thermal expansion is taken as zero for simplicity, as thermal strains alone are orders of magnitude smaller than transformation strains. The properties for the glass-epoxy are same as in [33] and shown in Table 2.

Table 1. Material properties for the Nitinol alloy used in the simulations of adaptive stiffening and shape control composites

\begin{tabular}{|l|l|l|l|}
\hline $\begin{array}{l}\text { Moduli, } \\
\text { density }\end{array}$ & $\begin{array}{l}\text { Transformation } \\
\text { temperatures }\end{array}$ & $\begin{array}{l}\text { Phase Diagram } \\
\text { parameters }\end{array}$ & $\begin{array}{l}\text { Max residual strain, } \\
\text { Poisson's ratio }\end{array}$ \\
\hline $\mathrm{D}_{\mathrm{A}}=3.94 \times 10^{6} \mathrm{psi}$ & $M_{\mathrm{f}}=43.16^{\circ} \mathrm{F}$ & $C_{\mathrm{M}}=644.4 \mathrm{psi} /{ }^{\circ} \mathrm{F}$ & $\varepsilon_{\mathrm{L}}=0.067$ \\
\hline$D_{\mathrm{M}}=1.97 \times 10^{6} \mathrm{psi}$ & $M_{\mathrm{s}}=68.9^{\circ} \mathrm{F}$ & $C_{\mathrm{A}}=1112 \mathrm{psi} /{ }^{\circ} \mathrm{F}$ & $v=0.3$ \\
\hline$\Theta=0 \mathrm{psi} /{ }^{\circ} \mathrm{C}$ & $A_{\mathrm{s}}=128.48^{\circ} \mathrm{F}$ & $\sigma_{\mathrm{s}}^{\mathrm{cr}}=14500 \mathrm{psi}$ & \\
\hline$\rho=0.2066 \mathrm{lb} / \mathrm{in}^{3}$ & $A_{\mathrm{f}}=142.34^{\circ} \mathrm{F}$ & $\sigma_{\mathrm{f}}^{\mathrm{cr}}=24650 \mathrm{psi}$ & \\
\hline
\end{tabular}

Table 2. Properties for the glass-epoxy matrix (Coefficient of thermal expansion is relative to $75 \mathrm{~F}$ and mass density is $0.07338 \mathrm{lb} / \mathrm{in}^{3}$ )

\begin{tabular}{|l|l|l|l|l|l|l|l|l|}
\hline $\mathrm{T}(\mathrm{F})$ & $\mathrm{E}_{1}(\mathrm{psi})$ & $\mathrm{E}_{2}(\mathrm{psi})$ & $v_{12}$ & $\mathrm{G}_{12}(\mathrm{psi})$ & $\mathrm{G}_{13}(\mathrm{psi})$ & $\mathrm{G}_{23}(\mathrm{psi})$ & $\mathrm{a}_{1}(1 / \mathrm{F})$ & $\mathrm{a}_{2}(1 / \mathrm{F})$ \\
\hline 60 & $7.15 \mathrm{E}+06$ & $2.90 \mathrm{E}+06$ & 0.29 & $1.40 \mathrm{E}+06$ & $1.40 \mathrm{E}+06$ & $1.40 \mathrm{E}+06$ & $2.928 \mathrm{E}-06$ & $6.139 \mathrm{E}-06$ \\
\hline 70 & $7.15 \mathrm{E}+06$ & $2.90 \mathrm{E}+06$ & 0.29 & $1.40 \mathrm{E}+06$ & $1.40 \mathrm{E}+06$ & $1.40 \mathrm{E}+06$ & $2.985 \mathrm{E}-06$ & $6.417 \mathrm{E}-06$ \\
\hline 80 & $7.15 \mathrm{E}+06$ & $2.90 \mathrm{E}+06$ & 0.29 & $1.40 \mathrm{E}+06$ & $1.40 \mathrm{E}+06$ & $1.40 \mathrm{E}+06$ & $3.155 \mathrm{E}-06$ & $7.253 \mathrm{E}-06$ \\
\hline 100 & $7.13 \mathrm{E}+06$ & $2.82 \mathrm{E}+06$ & 0.29 & $1.34 \mathrm{E}+06$ & $1.34 \mathrm{E}+06$ & $1.34 \mathrm{E}+06$ & $3.471 \mathrm{E}-06$ & $9.190 \mathrm{E}-06$ \\
\hline 120 & $7.11 \mathrm{E}+06$ & $2.75 \mathrm{E}+06$ & 0.29 & $1.29 \mathrm{E}+06$ & $1.29 \mathrm{E}+06$ & $1.29 \mathrm{E}+06$ & $3.677 \mathrm{E}-06$ & $1.068 \mathrm{E}-05$ \\
\hline 140 & $7.08 \mathrm{E}+06$ & $2.68 \mathrm{E}+06$ & 0.29 & $1.24 \mathrm{E}+06$ & $1.24 \mathrm{E}+06$ & $1.24 \mathrm{E}+06$ & $3.761 \mathrm{E}-06$ & $1.157 \mathrm{E}-05$ \\
\hline 150 & $7.07 \mathrm{E}+06$ & $2.64 \mathrm{E}+06$ & 0.29 & $1.22 \mathrm{E}+06$ & $1.22 \mathrm{E}+06$ & $1.22 \mathrm{E}+06$ & $3.771 \mathrm{E}-06$ & $1.184 \mathrm{E}-05$ \\
\hline 160 & $7.07 \mathrm{E}+06$ & $2.58 \mathrm{E}+06$ & 0.29 & $1.20 \mathrm{E}+06$ & $1.20 \mathrm{E}+06$ & $1.20 \mathrm{E}+06$ & $3.766 \mathrm{E}-06$ & $1.202 \mathrm{E}-05$ \\
\hline 180 & $7.06 \mathrm{E}+06$ & $2.47 \mathrm{E}+06$ & 0.29 & $1.15 \mathrm{E}+06$ & $1.15 \mathrm{E}+06$ & $1.15 \mathrm{E}+06$ & $3.735 \mathrm{E}-06$ & $1.220 \mathrm{E}-05$ \\
\hline 200 & $7.05 \mathrm{E}+06$ & $2.35 \mathrm{E}+06$ & 0.29 & $1.10 \mathrm{E}+06$ & $1.10 \mathrm{E}+06$ & $1.10 \mathrm{E}+06$ & $3.696 \mathrm{E}-06$ & $1.224 \mathrm{E}-05$ \\
\hline
\end{tabular}

Smart Structures and Materials 2005: Active Materials: Behavior and Mechanics, W. D. Armstrong, Editor, Proceedings of SPIE Vol. 5761 (SPIE, Bellingham, WA, 2005) Paper No. 84. 


\begin{tabular}{|l|l|l|l|l|l|l|l|l|}
\hline 220 & $7.05 \mathrm{E}+06$ & $2.22 \mathrm{E}+06$ & 0.29 & $9.80 \mathrm{E}+05$ & $9.80 \mathrm{E}+05$ & $9.80 \mathrm{E}+05$ & $3.671 \mathrm{E}-06$ & $1.223 \mathrm{E}-05$ \\
\hline 240 & $7.04 \mathrm{E}+06$ & $2.09 \mathrm{E}+06$ & 0.29 & $8.70 \mathrm{E}+05$ & $8.70 \mathrm{E}+05$ & $8.70 \mathrm{E}+05$ & $3.669 \mathrm{E}-06$ & $1.225 \mathrm{E}-05$ \\
\hline 250 & $7.04 \mathrm{E}+06$ & $2.03 \mathrm{E}+06$ & 0.29 & $8.10 \mathrm{E}+05$ & $8.10 \mathrm{E}+05$ & $8.10 \mathrm{E}+05$ & $3.677 \mathrm{E}-06$ & $1.228 \mathrm{E}-05$ \\
\hline 260 & $7.05 \mathrm{E}+06$ & $1.95 \mathrm{E}+06$ & 0.29 & $7.50 \mathrm{E}+05$ & $7.50 \mathrm{E}+05$ & $7.50 \mathrm{E}+05$ & $3.691 \mathrm{E}-06$ & $1.233 \mathrm{E}-05$ \\
\hline 280 & $7.06 \mathrm{E}+06$ & $1.80 \mathrm{E}+06$ & 0.29 & $6.20 \mathrm{E}+05$ & $6.20 \mathrm{E}+05$ & $6.20 \mathrm{E}+05$ & $3.726 \mathrm{E}-06$ & $1.247 \mathrm{E}-05$ \\
\hline 300 & $7.08 \mathrm{E}+06$ & $1.65 \mathrm{E}+06$ & 0.29 & $5.00 \mathrm{E}+05$ & $5.00 \mathrm{E}+05$ & $5.00 \mathrm{E}+05$ & $3.767 \mathrm{E}-06$ & $1.264 \mathrm{E}-05$ \\
\hline
\end{tabular}
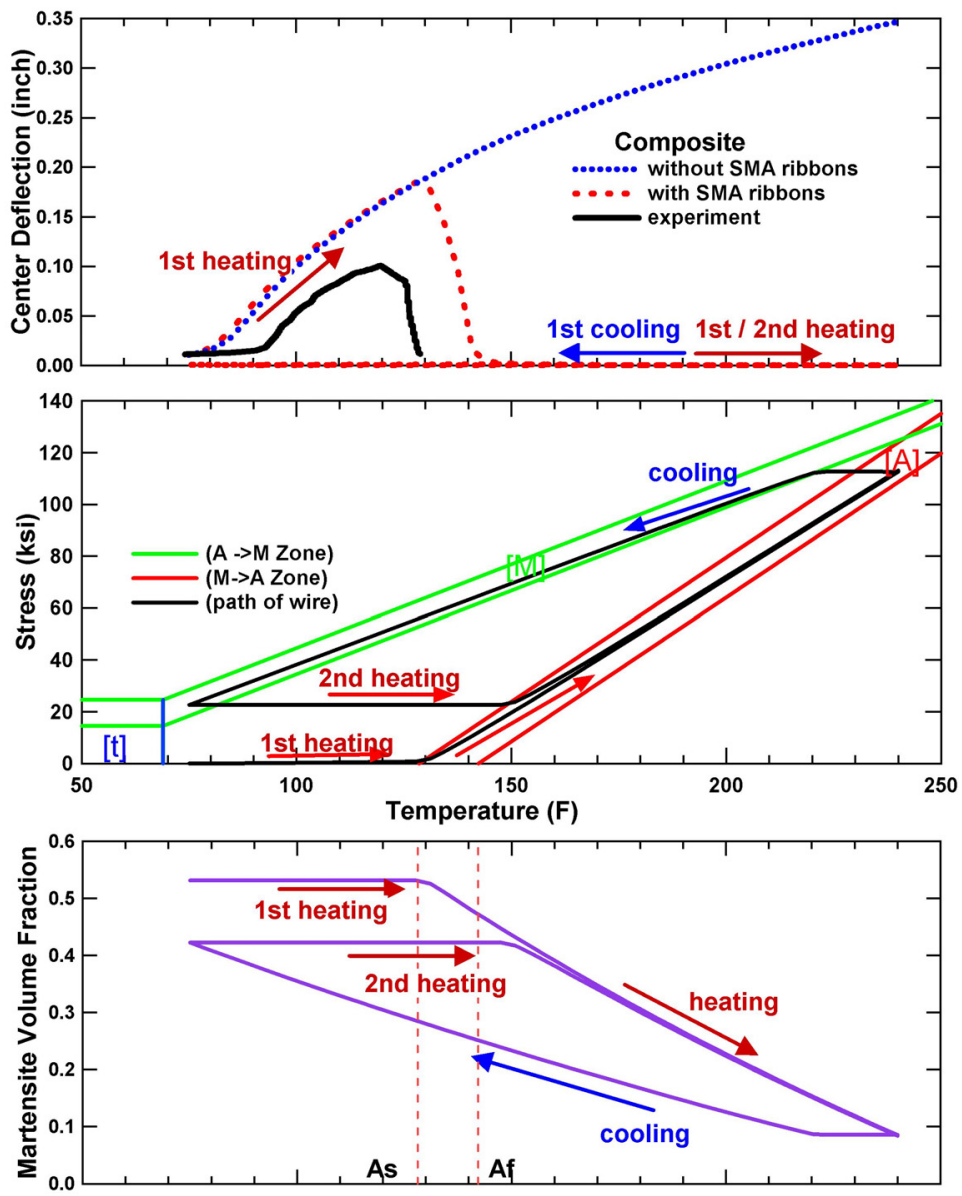

Figure 5: Top) Measured and predicted mid-span, post-buckling deflection versus temperature for the adaptive stiffening composite; Middle) Path in the phase diagram and Bottom) Martensite volume fraction versus temperature of the center shape memory element

The physical conditions for this specimen that are to be simulated numerically involve imposing a uniformly distributed thermal load of $240^{\circ} \mathrm{F}\left(115.6^{\circ} \mathrm{C}\right)$ in the presence of the clamped boundary conditions. The combination of the thermal loads and the fixed boundary conditions causes thermoelastic instability and large thermal post-buckling deflections. To prevent numerical ill conditioning, initial geometric imperfections were set as the resulting deflections calculated in a separate static analysis by applying a static gravity load of $\lg \left(386.4 \mathrm{in} / \mathrm{s}^{2}, 9.81 \mathrm{~m} / \mathrm{s}^{2}\right)$, normal to the plane of the beam.

Figure 5 shows change of several variables versus temperature including the measured and predicted mid-span, postbuckling deflection, the stress and the martensite volume fraction of the shape memory element. The mid-span, out-ofplane deflection versus temperature is shown in the top plot of Figure 5 for the experimental measurement, simulation of a simple composite (no SMA ribbons) and simulation of the active SMA composite. For the simulation of the simple composite, the traditional thermoelastic behavior prevails and the post-buckling deflection increases with temperature, with a deflection of 0.35 inch at $240^{\circ} \mathrm{F}$. For the active SMA composite, both the experimental result and the simulation show that the traditional thermoelastic behavior persists up to certain temperature (128.5F), at which point the SMA 
ribbons are actuated and begin to dominate the stress state. At higher temperatures, the structure is rendered flat, even eliminating the initial imperfection deflections, which is clearly shown at the beginning of all curves. An important condition to establish this buckling control is use of embedded SMA ribbons with an initial amount of detwinned martensite - the prestrain of the ribbons allows the large stresses to be incurred and the full recovery of the buckled shape. It is also noted that this self-stiffening effect is activated for any temperature above the reverse transformation temperature of the SMA elements used. As the critical temperature can be altered in SMAs with small changes in alloying elements and processing conditions, this adaptive stiffening can be designed for specific applications to have a significant effect on the structure's dynamic response. While the simulation accurately captures the qualitative response of the experiment, quantitative differences between the experimental data and the simulations remain and are due to several approximations. First, as mentioned earlier, currently the center region is modeled as only 12 layers of simple composite material and this reduces the moment of inertia. Therefore the simulation shows earlier post-buckling and a larger magnitude than exhibited in the experiment. In addition, in the experimental material the specimen is heated by resistive heating leading to a probably non-uniform of temperature distribution, while the simulation assumes constant temperature throughout the specimen. Finally, while some of the properties for the SMA were measured directly from the ribbons and used in the analysis, the parameters for the phase diagram is for a different material.

The middle and bottom plot of Figure 5 shows the path of the shape memory element in the SMA phase diagram and the detwinned volume fraction versus temperature respectively. The SMA element starts from a zero stress state with some initial detwinned volume fraction corresponding to $3.5 \%$ prestrain. No significant changes in the stress or volume fraction occur until the temperature reaches $\mathrm{A}_{\mathrm{s}}$ and the SMA element enters the reverse transformation zone [A]. At that point, the stress begins to increase and the volume fraction to decrease linearly with increase of temperature due to constraint on both ends. Note that the reverse transformation does not stop at $A_{f}$ since the reverse transformation region is shifted right at higher stress. During cooling, before the SMA element enters the transformation zone [M] the stress is constant since the post-buckling deflection has been diminished and cooling does not change the geometry appreciably. Once the SMA element enters the transformation zone [M], the high stress in the ribbon causes transformation from austenite to detwinned martensite, causing a decrease in the ribbon stress. By room temperature most of the stress has been released. Since the martensite volume fraction after cooling to room temperature is less than the original level before the $1^{\text {st }}$ heating, a stress of $23 p s i(159 \mathrm{MPa})$ in the ribbon remains to balance this volume fraction difference. In the second heating, there is no post-buckling due to this residual normal stress, although the stress does rise further and the martensite transformation occur with heating as indicated. Note that the transformation to austenite begins above the As temperature due to the residual normal stress. This simulation demonstrates the effectiveness and insight that can be gained using such a design and simulation tool.

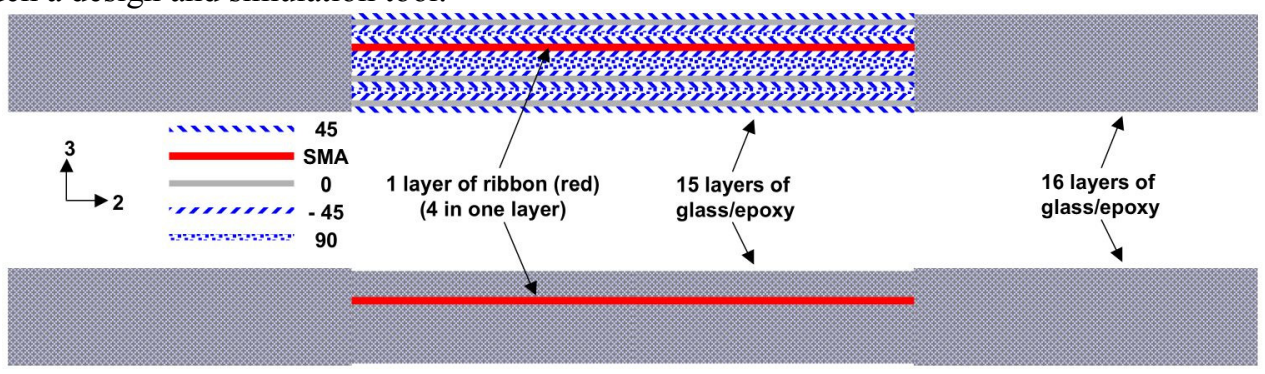

Figure 6: Top) Schematic of the cross-section of the shape-control prototype beam and Bottom) Finite element model.

\subsection{Cantilevered SMA hybrid composite beam}

The second example demonstrates shape/deflection control of a cantilevered SMA hybrid composite beam. Consider a cantilevered SMA hybrid composite beam that is 9 inches long $(22.86 \mathrm{~cm})$ and 1 inch wide $(2.54 \mathrm{~cm})$ and clamped one end with the other one free. The cross section of the beam is same as the top schematic in Figure 3 except the SMA ribbon material only replaces a width of 0.45 inch $(1.143 \mathrm{~cm})$ about the beam centerline in the 2 nd $0^{\circ}$ glass-epoxy layer as shown in the top schematic of Figure 6. Therefore, the prototype beam has a thickness of 0.078 inch $(0.1872 \mathrm{~cm})$ on both edges and 0.079125 inch $(0.2009775 \mathrm{~cm})$ in the center. As in the first example, the $2 \mathrm{D}$ layer of ribbons is modeled as a 1D truss element row, however in this case the geometric position off the neutral axis must be maintained in the simulation due to the lack of symmetry in the problem. Thus, the truss element is in the position of the 2 nd $0^{\circ}$ glass-epoxy layer and has equivalent cross-sectional area to the ribbon layer. Accordingly the matrix in the center is modeled as 15 
layers of glass-epoxy having a thickness of 0.073125 inch $(0.1857375 \mathrm{~cm})$, as shown in the bottom plot of Figure 6 . Once again the only connection between the SMA and the matrix is through the common nodes shared by the SMA and the matrix. The finite element mesh on the in-plane (top) view of the shape control SMA hybrid composite beam is shown in Figure 7.

\begin{tabular}{|c|c|c|c|c|c|c|c|c|c|c|c|c|c|c|c|c|c|}
\hline 109 & 110 & 111 & 112 & 113 & 114 & 115 & 116 & 117 & 118 & 119 & 120 & 121 & 122 & 123 & 124 & 125 & 126 \\
\hline 73 & 74 & 75 & 76 & 77 & 78 & 79 & 80 & 81 & 82 & 83 & 84 & 85 & 86 & 87 & 88 & 89 & 90 \\
\hline 37 & 38 & 39 & 40 & 41 & 42 & 43 & 44 & 4.5 & 46 & 47 & 48 & 49 & 50 & 51 & 52 & .53 & 54 \\
\hline 1 & 2 & 3 & 4 & .5 & 6 & 7 & 8 & 9 & 10 & 11 & 12 & 13 & 14 & 1.5 & 16 & 17 & 18 \\
\hline
\end{tabular}

Figure 7: In-plane view (top view) of the shape control SMA hybrid composite beam specimen ( $9 x 1$ inch), with $18 * 4$ matrix elements in a layer and crosses indicating the left end of user elements.
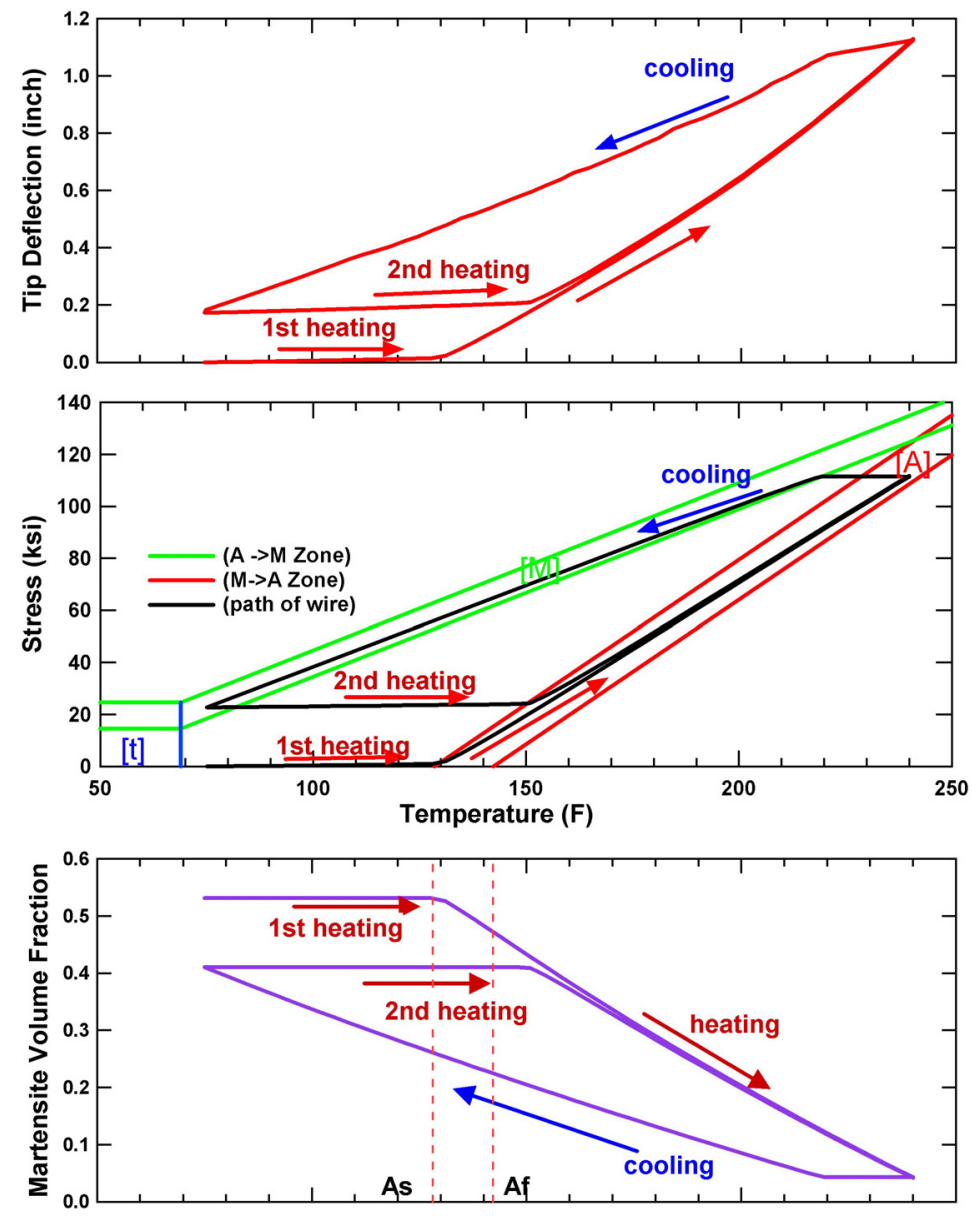

Figure 8: Top) Predicted tip-deflection versus temperature for the shape control composite; Middle) Path in the phase diagram and Bottom) Martensite volume fraction versus temperature of tip shape memory element

The model was subjected to a uniformly distributed thermal load of $240^{\circ} \mathrm{F}\left(121.1^{\circ} \mathrm{C}\right)$ to study the deflection response. No seeding of the deflection was necessary in this case due to the non-symmetric location of the SMA ribbons off the neutral axis. The tip displacement of the beam is shown in the top plot of Figure 8. Before the SMA elements enter the reverse transformation zone [A] the tip displacement increases very slowly due to the different thermal expansion coefficients of the matrix and composite. Thereafter tip deflection increases rapidly with temperature due to a combined effect of 
shortening of SMA ribbons and expansion of the polymer composite. Upon cooling, before SMA elements enter the detwinning martensite zone $[\mathrm{M}]$ the tip deflection drops slowly with decreasing temperature due to the pure thermoelastic effect. Thereafter tip deflection decreases rapidly with temperature. At room temperature, detwinned martensite remains as shown in the bottom plot of Figure 8 and therefore the stress in SMA elements is not zero, which accounts for a small tip deflection of 0.174 inch $(0.44149 \mathrm{~cm})$. One can see the large amount of change of tip displacement is due to the reverse or forward transformation of SMA ribbons. This example demonstrates the effectiveness of SMA ribbons in shape control. The middle plot of Figure 8 shows the path of the tip SMA element in the phase diagram and the bottom plot of Figure 8 shows the martensite volume fraction versus temperature. These two plots are quite similar to those in the adaptive stiffening simulation. As in the previous example, the use of prestrained SMA ribbons is essential to achieve significant shape control. Although thermal coefficient of expansion mismatch between the SMA elements and the composite can account for some shape change, the magnitude is insignificant compared to the actuated tip deflections using prestrained SMA ribbons.

In Figure 6, the SMA ribbons replaces the 2 nd $0^{\circ}$ glass-epoxy layer (16\% offset) and one expects larger tip displacement if the SMA ribbons replace the $1^{\text {st }} 0^{\circ}$ glass-epoxy layer ( $41 \%$ offset). Figure 9 shows the tip-deflection versus the relative position of the shape memory ribbon layer for the shape control composite. One can see the tip displacement increases linearly with the offset that the SMA ribbons are placed. By using such a flexible and robust design tool, one can obtain desired shape at specific temperatures by adjusting design parameters such as the lowest and highest temperatures, the prestrain amount, the composite configuration, and even material properties of the matrix and SMA.

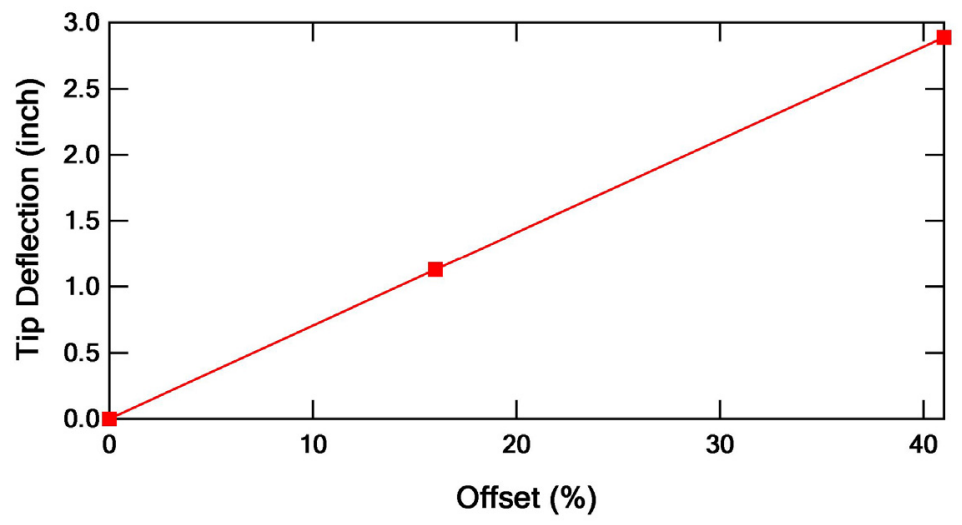

Figure 9: Tip-deflection versus the relative position of the shape memory ribbon layer for the shape control composite

\section{CONCLUSION}

In this paper, simulations of adaptive stiffening and shape control of SMA hybrid composites have been demonstrated and compared to experimental results. A rigorous 1D SMA model previously implemented using ABAQUS' user element interface has been used to simulate the 1D response of the SMA reinforcements in such composites. The matrix of these composites is modeled using standard element types available from ABAQUS by taking advantage of ABAQUS' available element types for laminated composite materials with temperature dependent material properties. Results from nonlinear static (post-buckling) analysis of a beam clamped at each end showed good correlation between experimental and simulation results. The deflection versus temperature response of a cantilevered beam demonstrated the efficient control authority of the embedded SMA. It can be concluded that SMAs are very good candidates for such composites and use of pre-strained SMA ribbons in these composites is critical.

An advantage of the simulation method developed here in which separate elements for the SMA reinforcements and matrix are used is that material properties or composite geometry can be changed easily. Other approaches in which special composite elements are developed which combine both SMA and matrix properties are more application specific. The flexibility and demonstrated robust performance in predicting self-healing, adaptive stiffening and shape control behavior of the current approach allows the technique to be used to achieve optimal design and explore design issues for a composite, including material properties for matrix and SMA, prestrain amount and volume percentage of the SMAs reinforcements, geometry arrangement and working temperature range for the composite. 


\section{FUTURE WORK}

In the future, beam's linear random response at select temperature will be performed and compared to experiments. Past experiments have shown large shifts in the resonant frequencies and reductions in the dynamic response amplitude. Debonding will be considered by adding interface elements connecting the matrix and the SMA elements, whose Young's modulus and yield strength will be replaced with a much lower value once the shearing stress of them exceeds certain threshold. Currently the SMA user element is a 3D truss and it cannot occupy a 2D or 3D space. A promising next step is to develop pseudo 2D or 3D user element based on the implemented 1D SMA model. The user specifies two edge or surfaces to whose centers the 3D SMA truss element will connect. Then the stiffness matrix and right hand side vector will be formed for ABAQUS to use.

\section{ACKNOWLEDGEMENT}

Funding support from NASA-Langley is gratefully acknowledged.

\section{REFERENCES}

1. Sittner, P., V. Michaud and J. Schrooten 2002. "Modelling and material design of SMA polymer composites", Materials Transactions, 43(5): 984-993.

2. Sun, S.S., G. Sun, F. Han and J.S. Wu 2002. "Thermoviscoelastic analysis for a polymeric composite plate with embedded shape memory alloy wires", Composite Structures, 58(2): 295-302.

3. Armstrong, W.D. 1996. "A one-dimensional model of a shape memory alloy fiber reinforced aluminum metal matrix composite", Journal of Intelligent Material Systems and Structures, 7(4): 448-454.

4. Song, G.Q., Q.P. Sun and M. Cherkaoui 1999. "Role of microstructure in the thermomechanical behavior of SMA composites", Journal of Engineering Materials and Technology-Transactions of the Asme, 121(1): 86-92.

5. Yue, Z.F. and J.S. Wan 2003. "Constitutive relationship and applications of shape-memory alloys", Progress in Experimental and Computational Mechanics in Engineering, 243-2: 487-491.

6. Watanabe, Y., E. Miyazaki and H. Okada 2002. "Enhanced mechanical properties of Fe-Mn-Si-Cr shape memory fiber/plaster smart composite", Materials Transactions, 43(5): 974-983.

7. Gupta, K., S. Sawhney, S.K. Jain and A.K. Darpe 2003. "Stiffness characteristics of fibre-reinforced composite shaft embedded with shape memory alloy wires", Defence Science Journal, 53(2): 167-173.

8. Hamada, K., F. Kawano and K. Asaoka 2003. "Shape recovery of shape memory alloy fiber embedded resin matrix smart composite after crack repair", Dental Materials Journal, 22(2): 160-167.

9. Lee, H.J., J.J. Lee and J.S. Huh 1999. "A simulation study on the thermal buckling behavior of laminated composite shells with embedded shape memory alloy (SMA) wires", Composite Structures, 47(1-4): 463-469.

10. Brinson, L.C., M.S. Huang, C. Boller and W. Brand 1997. "Analysis of controlled beam deflections using SMA wires", Journal of Intelligent Material Systems and Structures, 8(1): 12-25.

11. Lind, R.J. and C.C. Doumanidis 2003. "Active deformable sheets: prototype implementation, modeling, and control", Optical Engineering, 42(2): 304-316.

12. Oh, J.T., H.C. Park and W. Hwang 2001. "Active shape control of a double-plate structures using piezoceramics and SMA wires", Smart Materials \& Structures, 10(5): 1100-1106.

13. Aoki, T. and A. Shimamoto 2003. "Active vibration control of epoxy matrix composite beams with embedded shape memory alloy TiNi fibers", International Journal of Modern Physics B, 17(8-9): 1744-1749.

14. Brinson, L.C. and R. Lammering 1993. "Finite-Element Analysis of the Behavior of Shape-Memory Alloys and Their Applications", International Journal of Solids and Structures, 30(23): 3261-3280.

15. Lee, H.J. and J.J. Lee 2000. "A numerical analysis of the buckling and postbuckling behavior of laminated composite shells with embedded shape memory alloy wire actuators", Smart Materials \& Structures, 9(6): 780-787.

16. Birman, V. 1997. "Theory and comparison of the effect of composite and shape memory alloy stiffeners on stability of composite shells and plates", International Journal of Mechanical Sciences, 39(10): 1139-1149.

17. Boyd, J.G. and D.C. Lagoudas 1994. "Thermomechanical Response of Shape-Memory Composites", Journal of Intelligent Material Systems and Structures, 5(3): 333-346.

18. Araki, S., H. Ono and K. Saito 2002. "Micromechanical analysis of crack closure mechanism for intelligent material containing TiNi fibers - (1st report, modeling of crack closure mechanism and analysis of stress intensity factor)", Jsme International Journal Series a-Solid Mechanics and Material Engineering, 45(2): 208-216.

19. Shimamoto, A., J. Nam, T. Oguchi and T. Azakami 2001. "Effect of crack closure by shrinkage of embedded shape-memory TiNi fiber epoxy composite under mixed-mode loading", International Journal of Materials \& Product Technology: 263-268. 
20. Wang, X.M. 2002. "Shape memory alloy volume fraction of pre-stretched shape memory alloy wire-reinforced composites for structural damage repair", Smart Materials \& Structures, 11(4): 590-595.

21. Kawai, M., H. Ogawa, V. Baburaj and T. Koga 1999. "Micromechanical analysis for hysteretic behavior of unidirectional TiNiSMA fiber composites", Journal of Intelligent Material Systems and Structures, 10(1): 14-28.

22. Ghomshei, M.M., A. Khajepour, N. Tabandeh and K. Behdinan 2001. "Finite element modeling of shape memory alloy composite actuators: Theory and experiment", Journal of Intelligent Material Systems and Structures, 12(11): 761-773.

23. Sun, S.S., G. Sun and J.S. Wu 2002. "Thermo-viscoelastic bending analysis of a shape memory alloy hybrid epoxy beam", Smart Materials \& Structures, 11(6): 970-975.

24. Zak, A.J., M.P. Cartmell and W. Ostachowicz 2003. "Dynamics of multilayered composite plates with shape memory alloy wires", Journal of Applied Mechanics-Transactions of the Asme, 70(3): 313-327.

25. Ostachowicz, W., M. Krawczuk and A. Zak 1998. "Natural frequencies of multi-layer composite plate with embedded shape memory alloy wires", Journal of Intelligent Material Systems and Structures, 9(3): 232-237.

26. Lagoudas, D.C., D. Moorthy, M.A. Qidwai and J.N. Reddy 1997. "Modeling of the thermomechanical response of active laminates with SMA strips using the layerwise finite element method", Journal of Intelligent Material Systems and Structures, 8(6): 476-488.

27. Marfia, S., E. Sacco and J.N. Reddy 2003. "Superelastic and shape memory effects in laminated shape-memory-alloy beams", Aiaa Journal, 41(1): 100-109.

28. Turner, T.L., C.L. Lach and R.J. Cano 2001. "Fabrication and characterization of SMA hybrid composites", Proceedings of SPIE - The International Society for Optical Engineering, Society of Photo-Optical Instrumentation Engineers, 4333, pp.343-354.

29. Turner, T.L. 2000. "Dynamic response tuning of composite beams by embedded shape memory alloy actuators", Proceedings of SPIE - The International Society for Optical Engineering, Society of Photo-Optical Instrumentation Engineers, Bellingham, WA, USA, 3991, pp.377-388.

30. Lach, C.L., T.L. Turner, K.M. Taminger and R.N. Shenoy 2002. "Effects of thermomechanical history on the tensile behavior of Nitinol ribbon", Proceedings of SPIE - The International Society for Optical Engineering, The International Society for Optical Engineering, 4699, pp.323-334.

31. Turner, T.L. 2002. "Structural acoustic response of a shape memory alloy hybrid composite panel (lessons learned)", Proceedings of SPIE - The International Society for Optical Engineering, The International Society for Optical Engineering, 4701, pp.592603.

32. Turner, T.L., R.D. Buehrle, R.J. Cano and G.A. Fleming 2004. "Design, fabrication, and testing of SMA enabled adaptive chevrons for jet noise reduction", Proceedings of SPIE - The International Society for Optical Engineering, International Society for Optical Engineering, Bellingham, WA 98227-0010, United States, 5390, pp.297-308.

33. Turner, T.L. and H.D. Patel 2004. "Analysis of SMA hybrid composite structures using commercial codes", Proceedings of SPIE - The International Society for Optical Engineering, International Society for Optical Engineering, Bellingham, WA 98227-0010, United States, 5383, pp.82-93.

34. Turner, T.L. 2000. "A new thermoelastic model for analysis of shape memory alloy hybrid composites", J. Intell. Mater. Sys. Struct., 11(5): 382-394.

35. Gao, X., D.S. Burton and L.C. Brinson 2005. "Finite element simulation of a self-healing shape memory alloy composite", Mech. Mater., in press.

36. Zak, A.J., M.P. Cartmell, W.M. Ostachowicz and M. Wiercigroch 2003. "One-dimensional shape memory alloy models for use with reinforced composite structures", Smart Materials \& Structures, 12(3): 338-346.

37. Tanaka, K., S. Kobayashi and Y. Sato 1986. "Thermomechanics of Transformation Pseudoelasticity and Shape Memory Effect in Alloys", International Journal of Plasticity, 2(1): 59-72.

38. Liang, C. and C.A. Rogers 1990. "One-dimensional thermomechanical constitutive relations for shape memory materials", Journal of Intelligent Material Systems and Structures, 1(2): 207-234.

39. Brinson, L.C. 1993. "One Dimensional Constitutive Behavior of Shape Memory Alloys: thermomechanical derivation with nonconstant material functions", Journal of Intelligent Material Systems and Structures, 4(2): 229-242.

40. Brinson, L.C. and M.S. Huang 1996. "Simplifications and comparisons of shape memory alloy constitutive models", Journal of Intelligent Material Systems and Structures, 7(1): 108-114.

41. Bekker, A. and L.C. Brinson 1998. "Phase diagram based description of the hysteresis behavior of shape memory alloys", Acta Materialia, 46(10): 3649-3665.

42. Gao, X. and L.C. Brinson 2005. "Implementation of a 1D phase-diagram based SMA model using ABAQUS' user element interface while considering orientation, prestrain and compression", manuscript in preparation.

43. Liang, C. 1990. "The constitutive modeling of shape memory alloys", PhD, Virginia Tech.,

44. Dye, T.E. 1990. "An experimental investigation of the behavior of nitinol", MS, Virginia Tech. 